\title{
Temporal changes in crevasses in the middle Slessor Glacier, Coats Land, East Antarctica through SAR data analysis
}

\author{
Katsuaki Koike ${ }^{1}$, Hiroaki Yoshida ${ }^{2}$, Makoto Omura $^{3}$, Kazuo Shibuya ${ }^{4}$, and Koichiro Doi ${ }^{4}$ \\ ${ }^{1}$ Graduate School of Engineering, Kyoto University, Katsura C1-2-215, Kyoto 615-8540, Japan \\ ${ }^{2}$ Shinko Plantech Co., Ltd., Yokohama, Japan \\ ${ }^{3}$ Department of Environmental Science, University of Kochi, Kochi, Japan \\ ${ }^{4}$ National Institute of Polar Research and SOKENDAI, Tokyo, Japan
}

(Received October 5, 2010; Revised October 5, 2011; Accepted October 11, 2011; Online published March 12, 2012)

\begin{abstract}
Mosaic processing of SAR images by ERS 1/2 AMI revealed the detailed topography within a large valley (middle Slessor Glacier) in Coats Land, East Antarctica, showing oval and feather-shaped features that correspond to precipitous cliffs and accumulated crevasses, respectively. Time-series analysis of SAR intensity images acquired on six dates within the period October 1991 to August 2000 revealed the following topographic changes over time: (1) the feather-shaped feature moved down the slope at a rate of about $100 \mathrm{~m} /$ year; and (2) the extent of crevasse areas increased with time, both at the northern end of the feather-shaped feature and at the northeastern tip of the oval feature, with the increasing rates being much larger in the case of the feather-shaped feature. High increase ratios were generally correlated with a rapid increase in wintertime temperature within a short period of about 2 weeks: the relationship was approximated by an exponential function. Furthermore, we interpreted that the occurrence of a fault in the subglacial topography may have led to the initiation of ice fractures and a subsequent concentration of crevasses at the end of the feather-shaped feature.
\end{abstract}

Key words: ERS SAR, intensity image, interferometry, glacier, topography, temperature, tensile stress.

\section{Introduction}

As noted in the fourth report of the Intergovernmental Panel on Climate Change (Solomon et al., 2007), the accurate evaluation of anthropogenic effects on global climate change and related phenomena are important to ensure sustainable social development. Temporal change in glacier topography is one such phenomenon. Therefore, it is increasingly important to develop a comprehensive understanding of the interaction between global climate change and change in glaciers, including topography, melting, fracturing, and ow in polar regions.

An effective tool in gaining such an understanding is satellite remote sensing that provides periodic and synchronous Earth observations, particularly the SAR (synthetic aperture radar) microwave system, as it has the advantage over optical sensor systems of observing capability in both the daytime and nighttime and in any weather. This superiority of SAR has been demonstrated in many applications that involve interferometric and coherence tracking techniques using satellite SAR signal data to detect ow pattern and velocity in glaciers of Antarctica and the Arctic, e.g. Goldstein et al. (1993), Gray et al. (2001) and Joughin et al. (2004). Such interferometric techniques are useful only when glacier motion between two acquisition dates is relatively small, and the coherence of the image pair is high

Copyright (C) The Society of Geomagnetism and Earth, Planetary and Space Sciences (SGEPSS); The Seismological Society of Japan; The Volcanological Society of Japan; The Geodetic Society of Japan; The Japanese Society for Planetary Sciences; TERRAPUB.

doi:10.5047/eps.2011.10.003 enough to obtain an interferogram. However, interferometric techniques are not applicable in the case of large-scale, discontinuous change in glacier form (e.g. the generation and propagation of a crevasse, and abrupt changes in glacier topography) and for a data pair with a long time interval. Crevasse development might be related to global climate change. Knowledge of the generation pattern of crevasses may help in understanding the mechanism of glacier motion and in estimating the magnitude and direction of the driving force (gravitational force) behind such motion.

In the present study, we used SAR intensity images, among other data, to clarify in detail the long-term temporal changes in crevasse development in the middle part of the northern tributary of the Slessor Glacier, Coats Land, East Antarctica. This study area was chosen because it is a suitable setting in which to investigate the phenomena that occur in the upper stream of a large glacier with a relatively low ow velocity.

\section{Data Processing and Topographic Features 2.1 Study area}

Coats Land $\left(20-40^{\circ} \mathrm{W}, 75-80^{\circ} \mathrm{S}\right)$, East Antarctica, is bounded by the Filchner Ice Shelf to the west and the Weddell Sea to the north. The present study area (Fig. 1) is situated in the middle of the northern tributary of the Slessor Glacier, $20 \mathrm{~km}$ east of the Theron Mountains. In a previous study, based on airborne magnetic data and radioecho soundings, the main subglacial geologic units beneath the northern tributary of the Slessor Glacier were inferred to include a Precambrian block (bedrock in this region), 


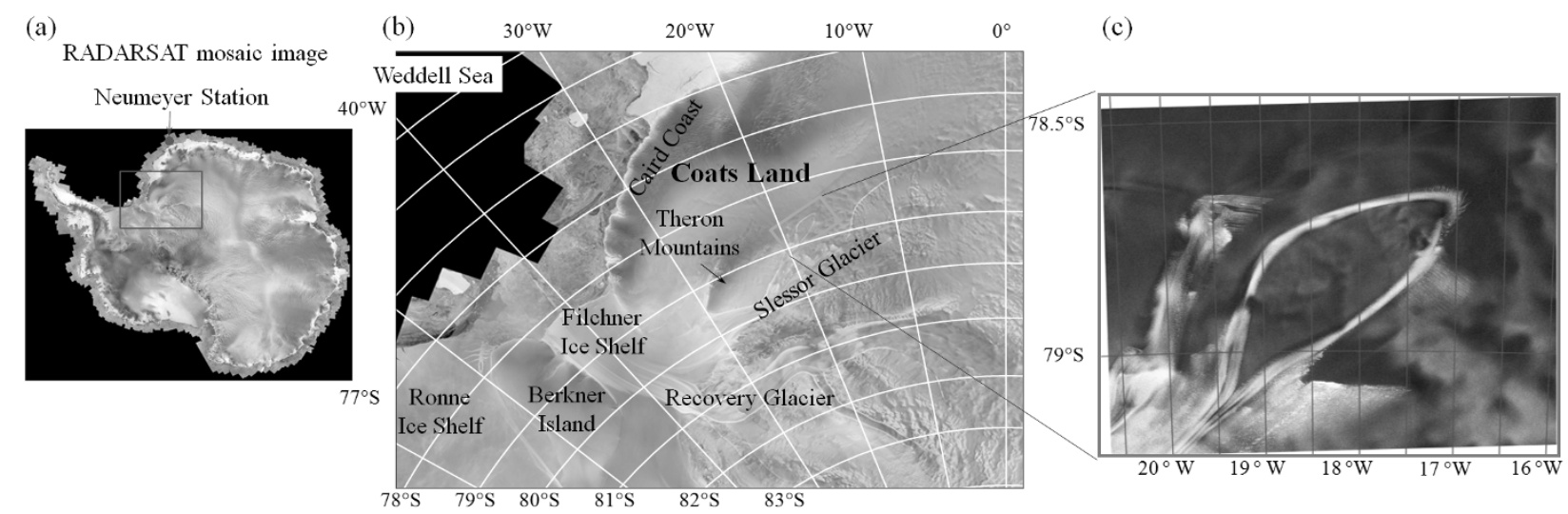

Fig. 1. Location of the study area in Coats Land, East Antarctica. The study area is situated in the middle of the northern tributary of the Slessor Glacier, $20 \mathrm{~km}$ east of the Theron Mountains. Data for the RADARSAT mosaic images (a) and (b) are from the National Snow and Ice Data Center (http://nsidc.org/data/radarsat/ramp_basics/basics.html). (b) Enlargement of the area shown by the rectangle in (a). (c) ERS-1/2 SAR image of the study area, as outlined by the rectangle in (b).

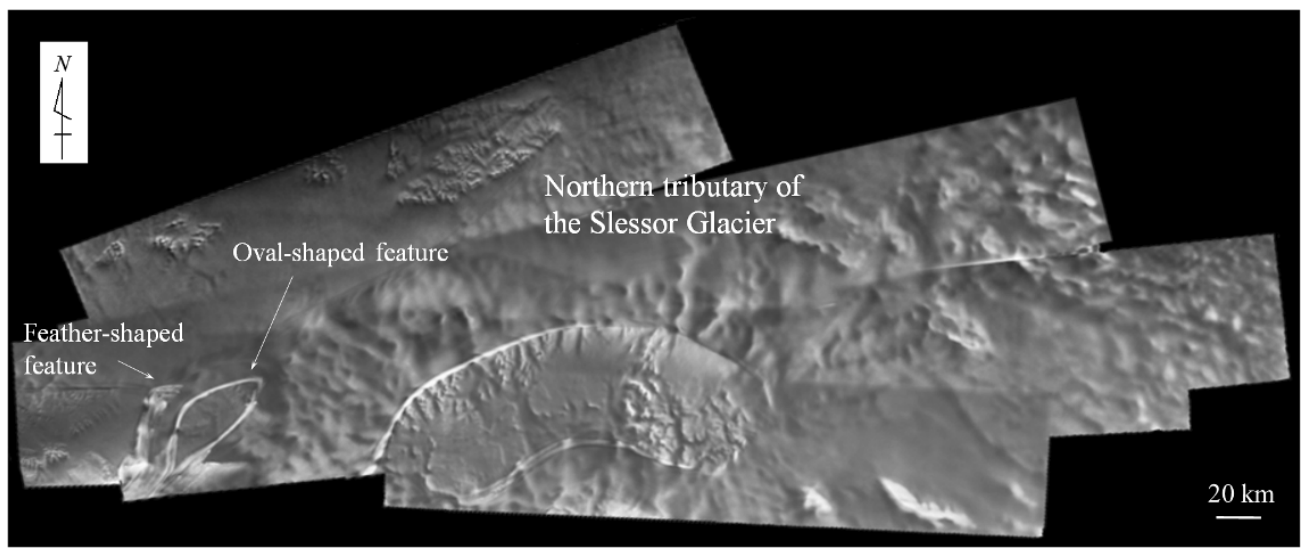

Fig. 2. Composite image of 89 scenes of ERS-1/2 SAR (covering an area of $616 \times 281 \mathrm{~km}$ ), showing the two bright curves in the lower middle of the image and the traces of ice ow at the downstream foot of the oval feature and at the feather-shaped feature to the west.

Jurassic dykes and sills, and a younger sedimentary basin (Shepherd et al., 2006). The results of forward and inverse magnetic modeling undertaken by these authors suggest that the Slessor Glacier is underlain by a 3-km-thick sedimentary layer deposited in a bedrock depression. Of note, several magnetic lineaments are oriented obliquely to the topographic troughs that contain the northern, central, and southern tributaries of the Slessor Glacier; these lineaments were interpreted to represent faults.

Marsh (1985) identi ed many lineaments in the Theron Mountains area based on satellite imagery using nearinfrared Ladsat MSS (Multispectral Scanner) and NOAA (National Oceanic and Atmospheric Administration) images, and proposed that (1) the region is a mosaic of segments bounded by faults, (2) lineaments oriented subparallel to the escarpment and major valleys of the Theron Mountains may indicate the presence of fractures associated with Mesozoic rifting along the Weddell Sea and Filchner Ice Shelf, and (3) discontinuities in the ice surface topography may be related to bedrock scarps and discontinuities in the upper surface of bedrock.

The most conspicuous topographic feature of the glacier surface in the study area is an oval feature that is $60 \mathrm{~km}$ along its long axis (NE-SW) and $30 \mathrm{~km}$ along its short axis
(NW-SE), as shown in Fig. 1(c). Marsh (1985) inferred that this topography was formed in response to discontinuities in bedrock elevation and a dissected scarp, and that most of the ow of the glacier passes around it.

\subsection{SAR data}

To analyze crevasse development, we selected 89 scenes of ERS-1/2 AMI (European Remote-Sensing Satellites 1/2 Active Microwave Instrument) data around the study area, as acquired at Syowa Station $\left(69.0^{\circ} \mathrm{S}, 39.5^{\circ} \mathrm{E}\right)$ from October 1991 to June 2000. As the rst step of analysis, the region including the oval feature was represented by a composite SAR intensity image covering an area of $616 \times 281 \mathrm{~km}$ (Fig. 2). This image was produced by a GIS technique that involved mosaicing, geometrical correction, and brightness adjustment by selecting tie points in the neighboring images. We sought to identify crevasses in detail from the mosaic image, which emphasizes the crevasse distribution, rather than from extensive imagery from the satellite Argon photographs (Kim et al., 2007) and from the RADARSAT Antarctic Mapping Project (RAMP; e.g. Jezek, 2008).

The image brightness is proportional to backscatter intensity: bright pixels correspond to rough glacial surface, whereas dark pixels indicate smooth surface. Rough glacial surface includes thinning of the top snow layer, sastrugi for- 

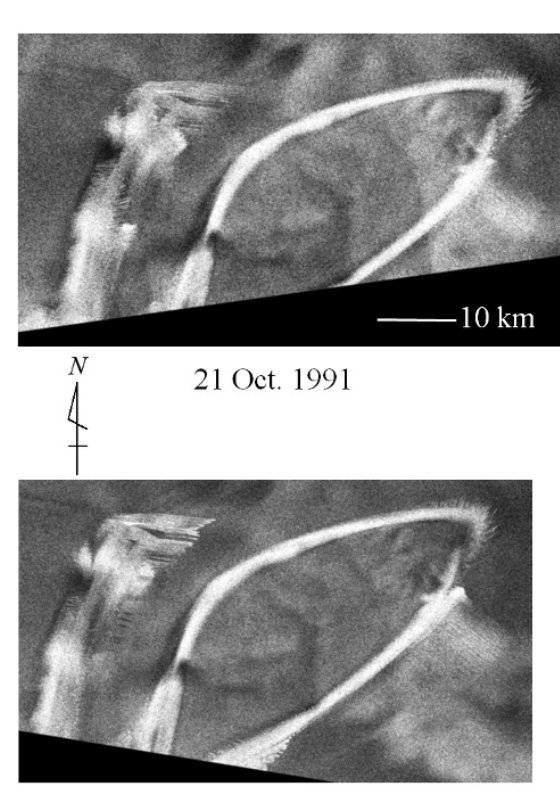

31 Jan. 1997

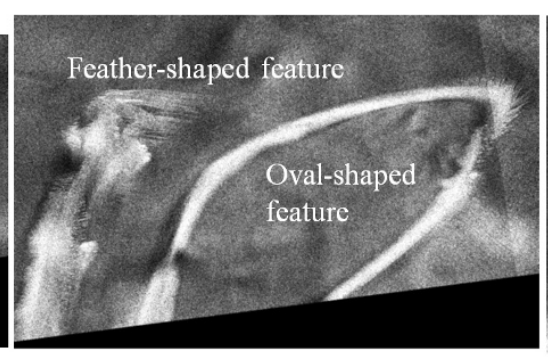

15 Aug. 1992

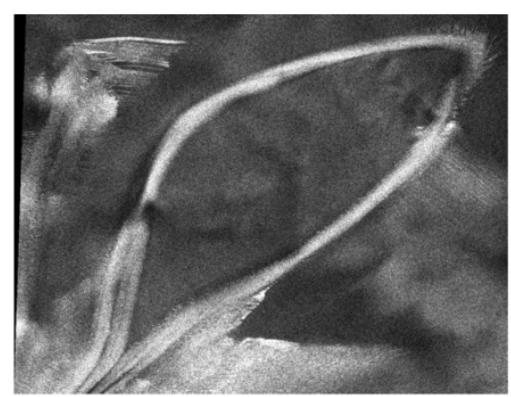

14 Mar. 2000

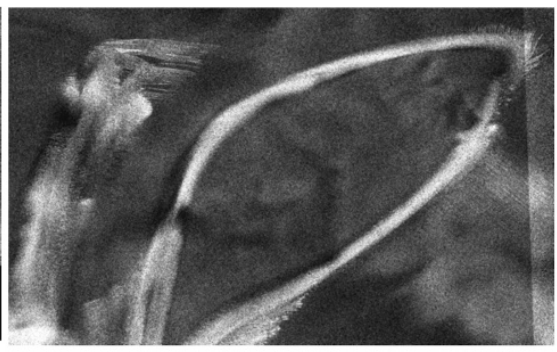

21 Aug. 1994

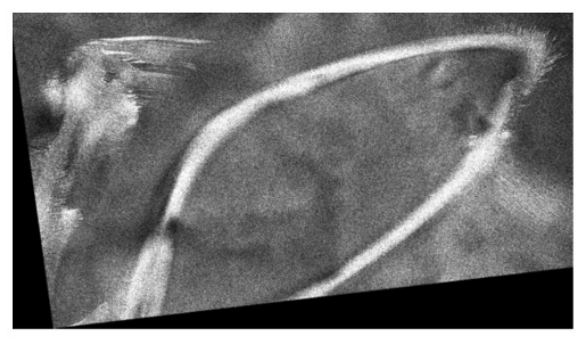

3 Aug. 2000

Fig. 3. Multilook detected SAR intensity images acquired on six different dates (see Table 1), highlighting the oval and feather-shaped features.

mation, crevasses, and scarps. Among them, we interpreted crevasses as continuous, systematic bright patterns that are linear or gently curved and are distributed parallel to each other. The patterns are at the order of kilometers in length.

The two bright curves in the lower middle of the image (Fig. 2) may represent large ridges or scarps rather than crevasses, as they seem to be located in highlands and small, continuous features cross the curves at right angles. Traces of ice ow are evident at the downstream foot of the oval feature and at the feather-shaped feature to the west. Such a combination of two peculiar topographies (the oval and feather-shaped features) has not been reported from other areas of Antarctica. SAR is suitable to analyze these features in detail. Accordingly, we focus on these features with the aim of understanding the origin and development of crevasses in the upper stream of a glacier.

Among the 89 considered scenes, the 10 scenes ( 6 acquisition dates) listed in Table 1 were used for crevasse analysis. In the case that the oval and feather-shaped features extended over two scenes, they were mosaiced into a single scene. The resulting six scenes were co-registered into a common coordinate system (Fig. 3), yielding MLD (multilook detected) intensity images generated from the raw SAR signal data with a spatial resolution of $12.5 \mathrm{~m} / \mathrm{pixel}$.

It is dif cult to clearly distinguish the oval and feathershaped features from optical-sensor satellite images, even under ne weather conditions. Figure 4 shows two examples of optical-sensor satellite images without cloud cover: a mosaic of two Terra/ASTER scenes (Fig. 4(a)) obtained on 7 January 2006 (path 172, row 320 and path 169, row 322) and one scene of Landsat ETM+ (Fig. 4(b)) obtained on 11 January 2000 (path 169, row 117). Both features are seen in visible to near-infrared color composite images assigned data of the three shortest wavelength bands (blue, green, and red; inset in each gure). The two features and ow traces are ambiguous on the ASTER image, but are
Table 1. Speci cations of ERS-1/2 SAR data used for crevasse analysis. $\mathrm{D}$ and $\mathrm{A}$ represent descending and ascending orbit mode, respectively.

\begin{tabular}{ccccc}
\hline Acquisition date & Path & Row & Satellite & Mode \\
\hline 21 Oct. 1991 & 265 & 438 & ERS-1 & D \\
21 Oct. 1991 & 273 & 438 & ERS-1 & D \\
\hline 15 Aug. 1992 & 265 & 438 & ERS-1 & D \\
15 Aug. 1992 & 273 & 438 & ERS-1 & D \\
\hline 21 Aug. 1994 & 269 & 439 & ERS-1 & D \\
21 Aug. 1994 & 277 & 439 & ERS-1 & D \\
\hline 31 Jan. 1997 & 269 & 438 & ERS-2 & A \\
31 Jan. 1997 & 265 & 438 & ERS-2 & A \\
\hline 14 Mar. 2000 & 269 & 438 & ERS-2 & D \\
3 Aug. 2000 & 269 & 438 & ERS-2 & D \\
\hline
\end{tabular}

appeared weakly on the ETM+ image. It is evident from Figs. 2 and 3 that topographic relief is more clearly visible in the SAR images than in the ETM+ image. Opticalsensor images represent the re ectance of surface materials for the sun's illumination at selected wavelength. The above unclearness is caused probably by similarity of the re ectances of the features to those of the surroundings, although their topographic reliefs are different largely.

Image-to-image cross-correlation has been applied previously to pairs of optical sensor images to automatically track crevasses in mapping the velocity eld of glacier motion and deformation (Scambos et al., 1992; Whillans and 
(a)

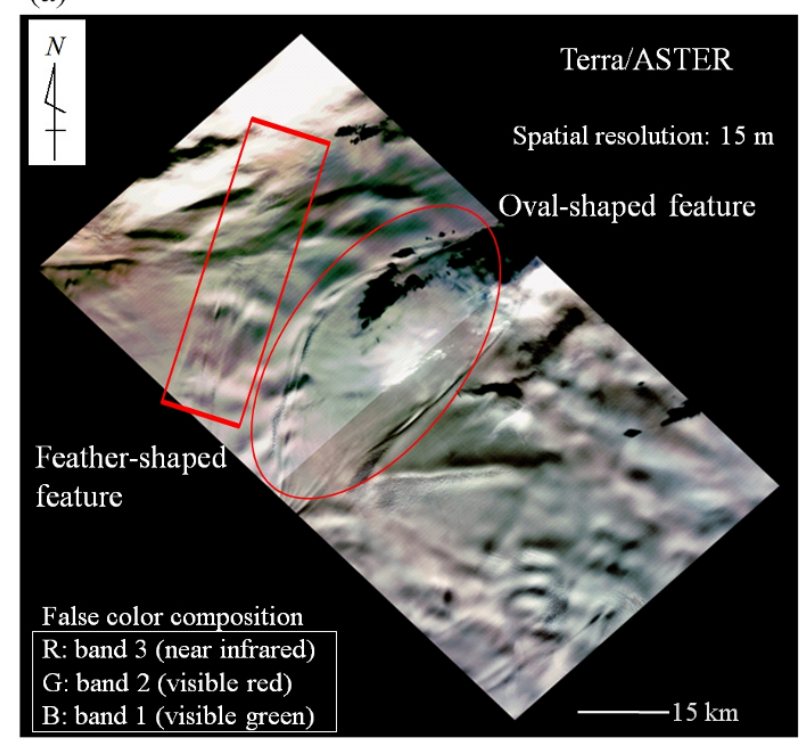

(b)

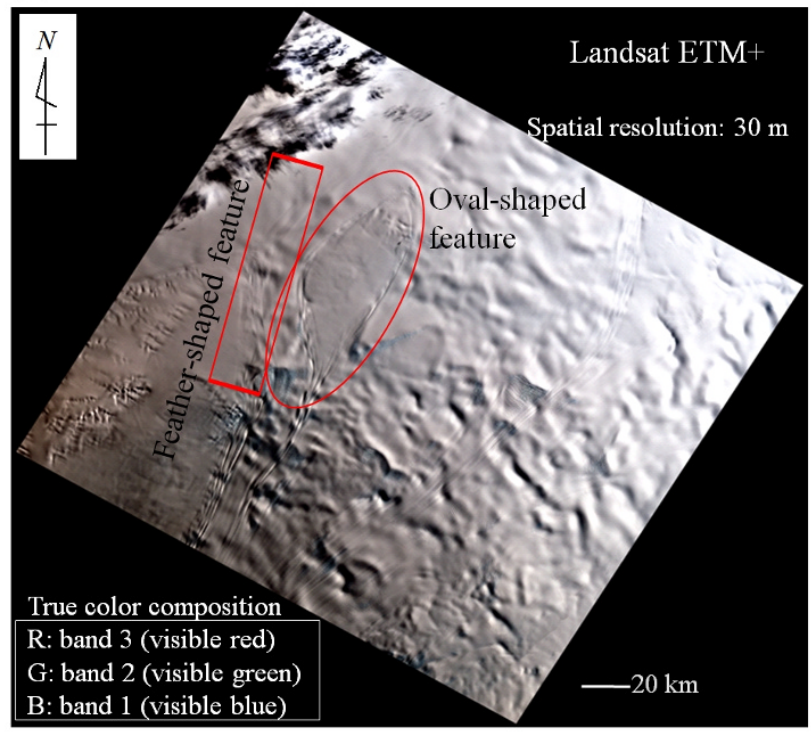

Fig. 4. Optical sensor images of the study area. (a) A mosaic of two Terra/ASTER scenes obtained on 7 January 2006 (path 172 , row 320 and path 169, row 322). (b) A Landsat ETM+ scene captured on 11 January 2000 (path 169, row 117). Using these imaging techniques, the oval and feather-shaped features are only evident under fine weather conditions. The features are appeared in visible to near-infrared color composite images in which the three shortest-wavelength band data are assigned to RGB.

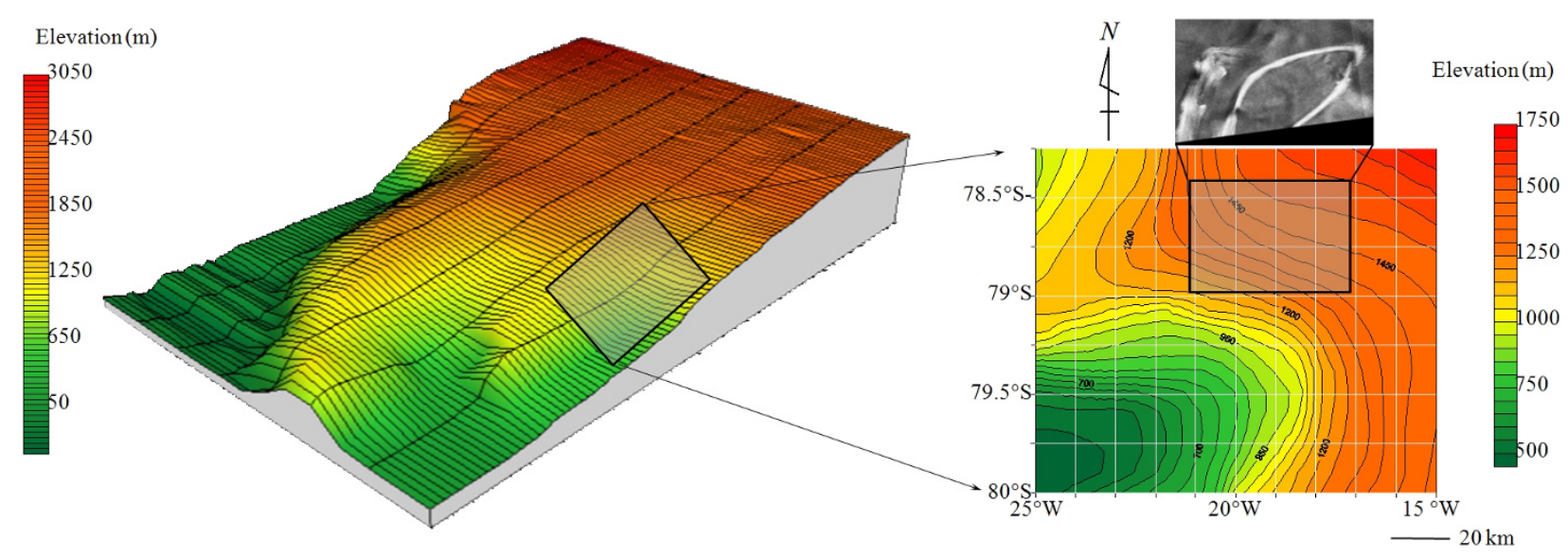

Fig. 5. SAR intensity image overlaid upon a digital elevation model (DEM) with a 400-m mesh, as compiled by the RADARSAT Antarctic Mapping Project (Liu et al., 2001).

Tseng, 1995). However, the crevasses were subtle on optical sensor images and data obtained under fine conditions are limited. The cross-correlation technique is unsuitable in the present case; consequently, the use of SAR image data is most effective in detecting temporal changes in crevasses, including their generation, opening, propagation, and displacement.

\subsection{Topographic characterization}

A digital elevation model (DEM; 400-m mesh) compiled by RAMP (Liu et al., 2001) shows that the study area is located on a slope that dips $0.4^{\circ}$ to the southwest (Fig. 5). Flow traces are directed from the bottom of the oval and feather-shaped features are located toward a large valley that corresponds to the central part of the Slessor Glacier.

To extract more detailed topographic features, a DEM of the study area was generated based on the Interferometric SAR (InSAR) technique, using an ERS-1 image pair (path
269, row 438) at the ascending mode; the images were acquired 3 days apart (7 and 10 December 1991) with a $146 \mathrm{~m}$ perpendicular baseline. We processed all combinations of the available ERS-1/2 data and JERS-1, but an interferogram was obtained over the study area only with the above-mentioned pair. Figure 6(a) shows an interferogram after flattening, which removes the fringe that originates from the difference in orbits of the two images. The interferogram includes information on topography and its changes between the acquisition dates; however, the latter effect is negligible as the acquisition interval is short (3 days). Therefore, the interferogram can be used to generate a DEM by phase unwrapping and to clarify the details of topography.

Figure 6(b) shows the resulting DEM, including oblique views from the southwest (bottom panel) and northeast (top panel). Because there is no ground control point in the study 
(a)

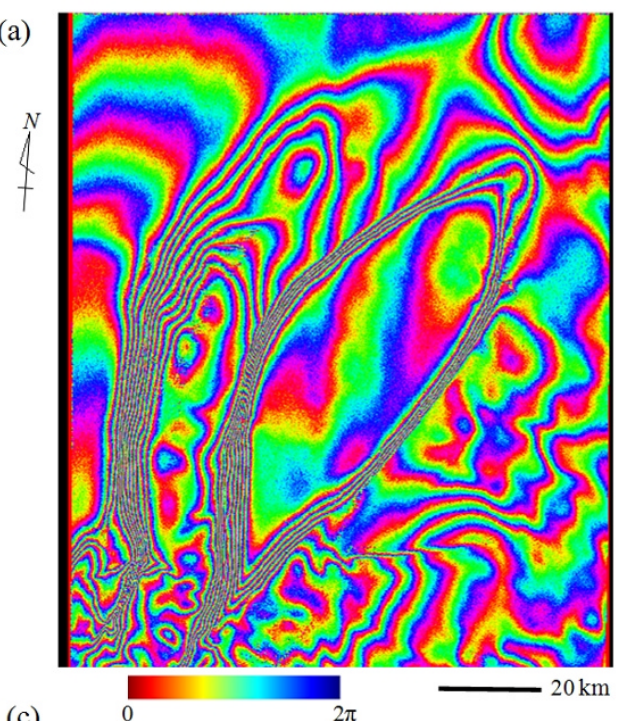

(c)

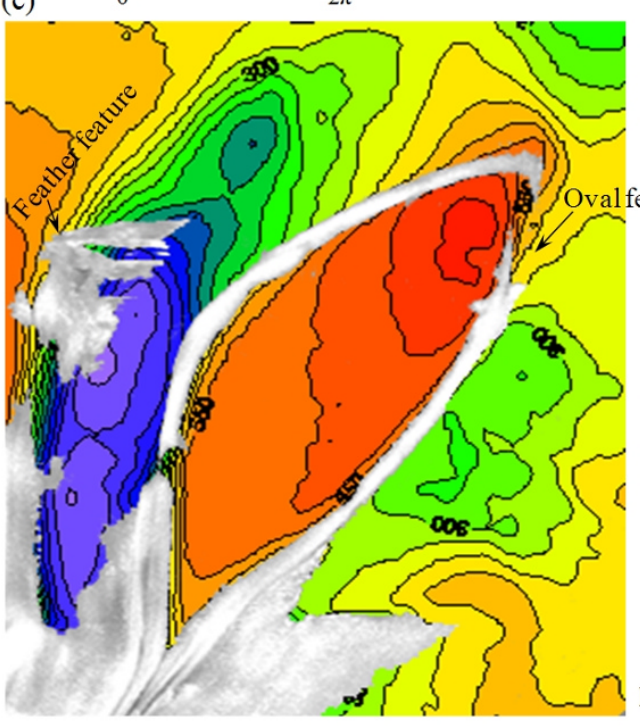

(b)

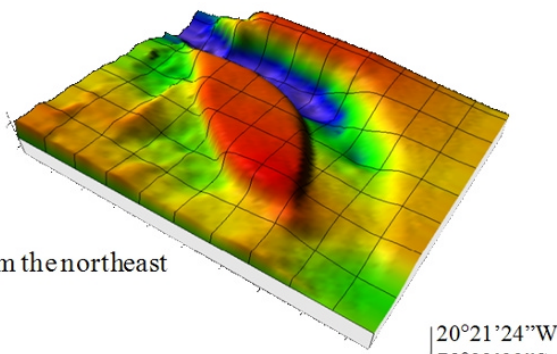

Perspective view from the northeast
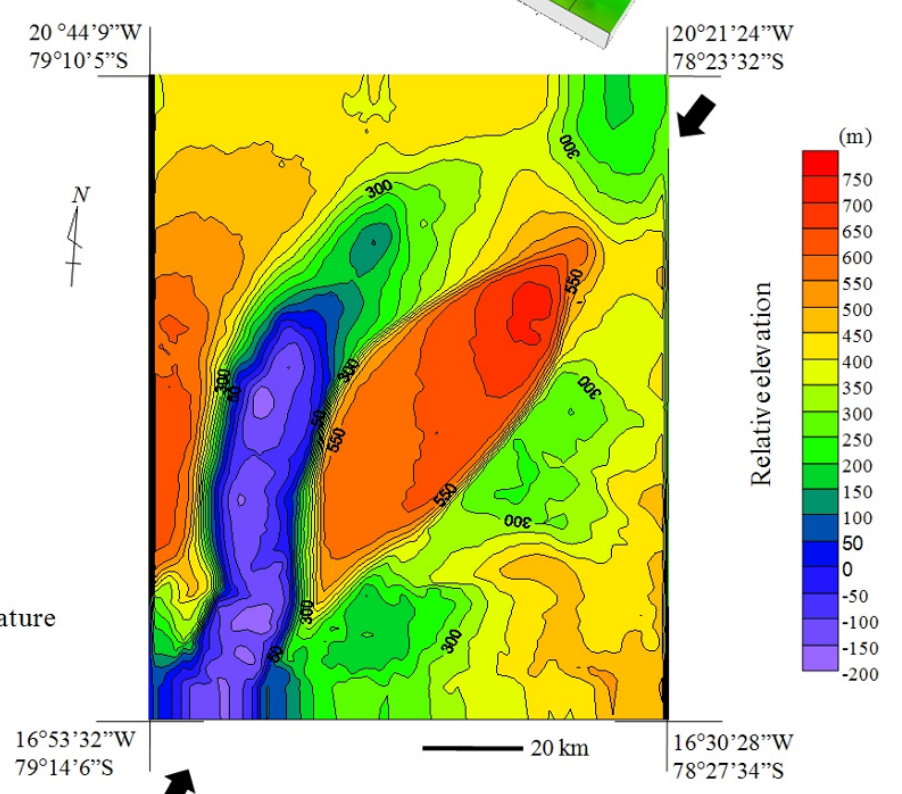

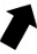

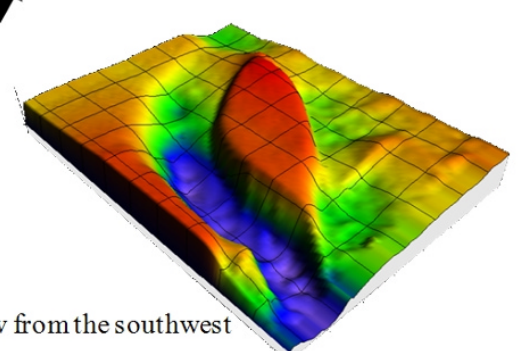

Fig. 6. Interferometric SAR based on an ERS-1 image pair (path 269, row 438) at the ascending mode with an acquisition interval of 3 days (7 and 10 December 1991) and a $146 \mathrm{~m}$ perpendicular baseline. (a) Interferogram after flattening, which removes the fringes that originate from differences in orbits between the two images. (b) Resulting DEM and perspective views. (c) Superposition of a SAR intensity image onto the DEM. Elevation in the DEM is shown as relative values from a certain phase.

area, elevation in the DEM is relative to a certain phase, but is roughly scaled to the RAMP DEM. According to Liu $e t$ al. (2001), the vertical accuracy of the RAMP DEM ranges from $\pm 7.5 \mathrm{~m}$ for the gently sloping interior of the ice sheet to $\pm 100 \mathrm{~m}$ over rugged mountainous areas. The vertical accuracy of the DEM in Fig. 6(b) is unknown, but the height differences $(150-500 \mathrm{~m})$ in the following discussions exceed the largest error in the RAMP DEM. Consequently, topographic features can be detected from our DEM. Three remarkable topographic features are apparent: (1) the oval feature is surrounded by a steep scarp of about $500 \mathrm{~m}$ in height in the west and $300 \mathrm{~m}$ in the east; (2) the surface of the oval feature is flat (relief of only $150 \mathrm{~m}$ ), and dips gently to the southwest along its long axis; and (3) the feathershaped feature is in a deep valley flanked by high scarps on both sides. Superposition of a SAR intensity image on the DEM reveals that the high backscatter from the rim of the oval feature originates from the scarp, and that the feather- shaped feature is located from the western scarp to the central part of the valley (Fig. 6(c)). In addition, the tip of the feather-shaped feature corresponds with the northern margin of the trough within the valley which is shown by the northern boundary of bluish colors.

\section{Temporal Changes in Crevasse Area}

\subsection{Location of the zone of concentrated crevasses}

Zones of concentrated crevasses are observed at the northeastern tip of the oval feature and at the northern end of the feather-shaped feature. Figure 7 compares three SAR intensity images obtained in October 1991 (bottom left), January 1997 (bottom center), and March 2000 (bottom right). From 1991 to 1997 , the end zone of the feathershaped feature became larger (see the yellow oval in the figure). Several large crevasses are newly formed (over $450 \mathrm{~m}$ in width and $15 \mathrm{~km}$ in length) in the March 2000; and new crevasses appeared to connect the existing crevasses in a 


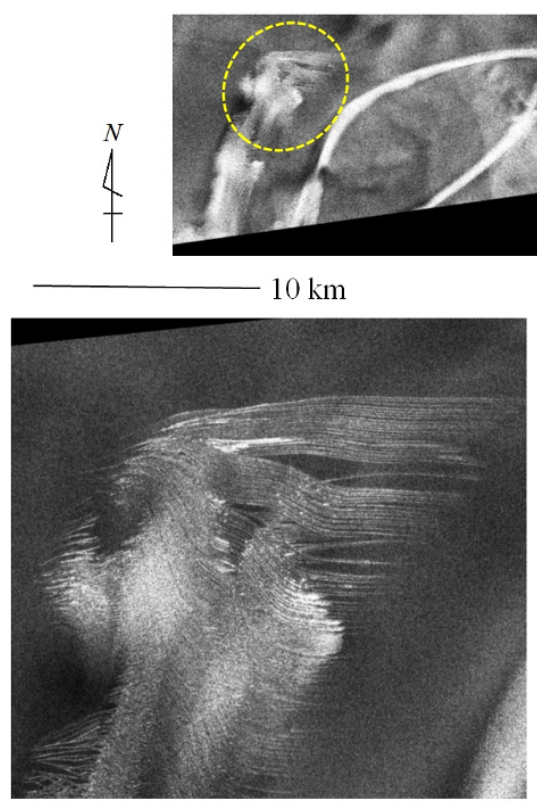

21 Oct. 1991

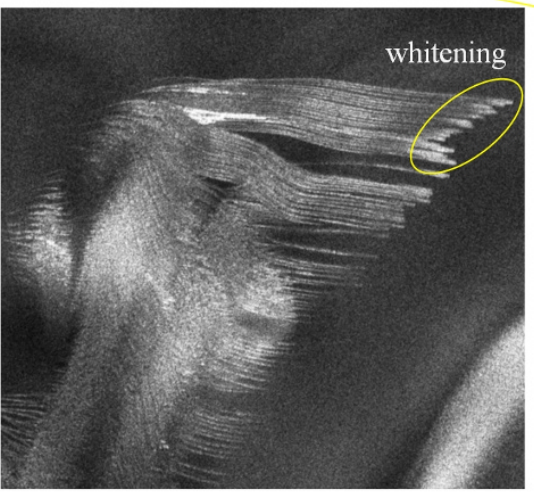

31 Jan. 1997

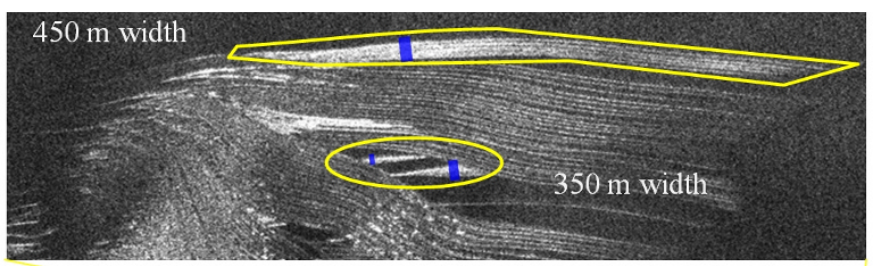

$10 \mathrm{~km}$

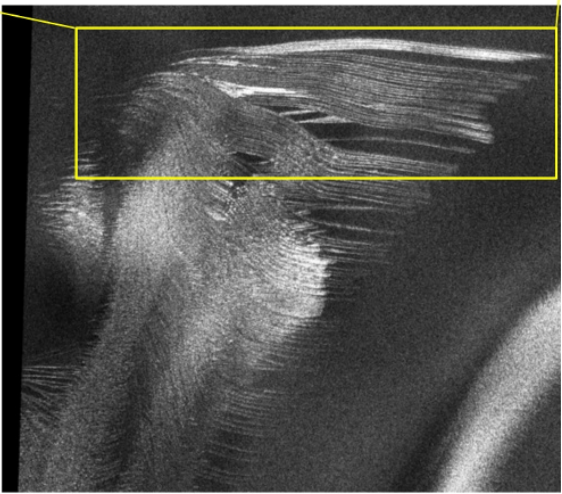

14 Mar. 2000

Fig. 7. SAR intensity images obtained in October 1991, January 1997, and March 2000. An enlargement of the end zone of the feather-shaped feature (dashed circle) shows the formation and propagation of new crevasses as white areas in the images (see also the yellow oval and polygon in the enlargement of the March 2000 image). Blue marks indicate the widths of new crevasses.
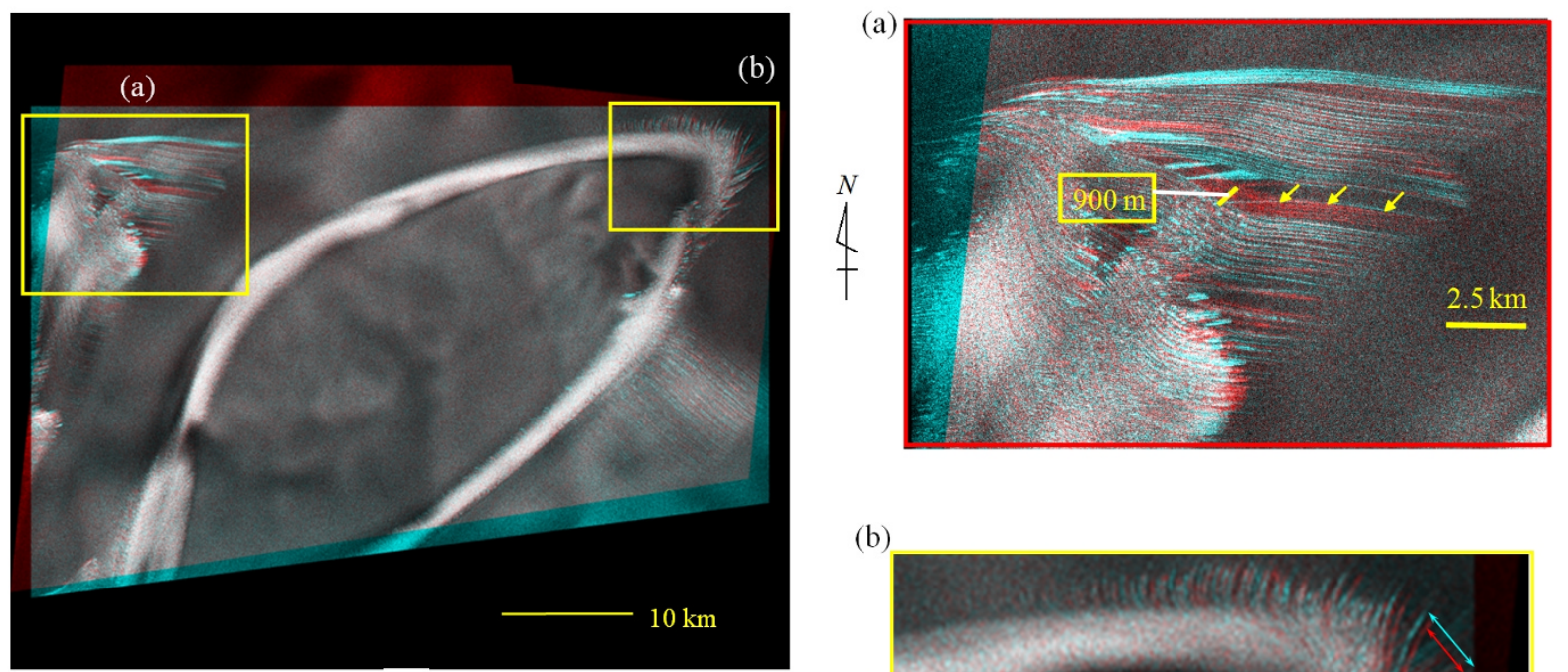

(b)

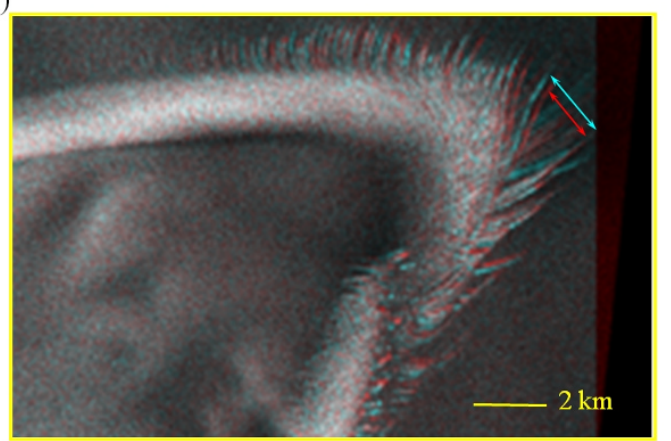

Direction of movement

Fig. 8. Movement of crevasses observed from an overlay of the co-registered oldest (October 1991) and most recent (August 2000) images. (a) Displacement at the end of the feather-shaped feature is $900 \mathrm{~m}$ toward the southwest. (b) Change in the location of crevasses at the tip of the oval feature, indicating that the spacing between crevasses may have increased. The direction of movement is also shown on a DEM with a 400-m mesh (see also the right side of Fig. 5). 

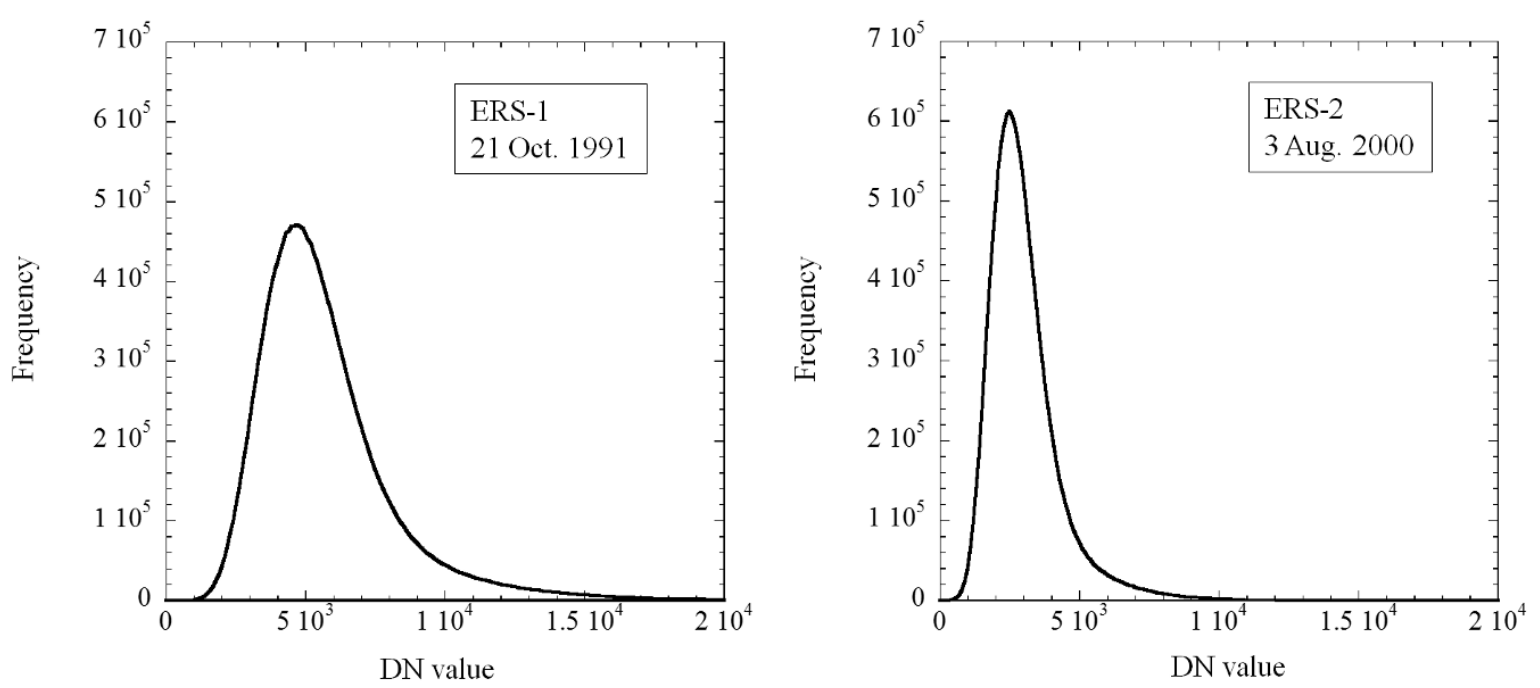

Fig. 9. Examples of histograms of DN (digital number) values that comprise a SAR intensity image.

form resembling bridges (yellow oval in the enlargement of the March 2000 scene). Whitening of the tips of crevasses indicates an increase in surface roughness, which is caused by new fracturing and development of the crevasses or snow conditions such as deposition of new snow layers on the surface. The new fracturing is more probable than the other phenomena, because the others can cause the whitening over the crevasses not only on the tips.

In addition to crevasse generation and extension, crevasse motion can be observed from an overlay of the co-registered oldest (October 1991) and most recently obtained (August 2000) images (Fig. 8(a)). The error of co-registration was set to be smaller than one pixel $(12.5 \mathrm{~m})$. The overlay indicates $900 \mathrm{~m}$ of movement toward the southwest, toward the valley bottom as shown by the black arrow in the gure. Considering the time interval between the two images ( 8 years and 9.5 months), the average velocity for this period is $103 \pm 1 \mathrm{~m}$ /year, consistent with the ice surface velocity around the study area determined by a combination of InSAR-derived velocities and balance velocities (Shepherd et al., 2006). Consequently, the feather-shaped feature was found to ow, accompanied by the generation and extension of crevasses. Matching between descendingand ascending-mode images was insuf cient for measuring velocity in other image pairs listed in Table 1.

Figure 8(b) shows temporal changes in crevasse patterns located at the tip of the oval feature, as assessed over the longest time interval. The crevasse motion is less clear than that in the feather-shaped feature; however, it appears that the spacing between crevasses has increased as shown by the opening of two arrows in Fig. 8(b), possibly due to subsidence at the tip of the feature.

\subsection{Binarization for extracting crevasses}

To clarify the nature of temporal change in the areal extent of crevasses, they were extracted by binarization, which is an established image-processing technique used to divide the original image into target and background. Figure 9 shows two histograms of DN (digital number) values that comprise a SAR intensity image of the study area in Fig. 8. Because there exists no bimodality in the frequency that can be used as a basis to separate target (crevasse) from background (non-crevasse), the de nition of a suitable threshold DN value (to separate target from background) is the most important task in performing the binarization. We used two methods in this regard: a manual de nition that searches for a suitable threshold by repeatedly changing the threshold and evaluating the result at each step, and the automatic de nition developed by Otsu (1980), which determines the threshold such that the sum of variances in two classes is minimized and the variance between the classes is maximized.

Figure 10 compares the results of manual and automatic methods for the image obtained in October 1991. Enlargements of the analyzed areas reveal that thin crevasses can be distinguished in the images obtained using the manual method, whereas such crevasses remain clouded in the images obtained using the automatic method. Although the automatic method is less time consuming, it is less effective when applied to complicated targets such as crevasses, which are thin, closely spaced, and show variable DN values according to the degree of surface roughness. Consequently, we chose the manual method to calculate temporal changes in crevasse area. It is evident that the extent of crevasse areas has increased with time, at both the end of the feather-shaped feature (black dots) and the tip of the oval feature (white diamonds), although the rates of increase are different: the rate is 3.6 times greater on the average over the period at the feather-shaped feature (Fig. 11(a)). Because of differences in sensitivity to the tension along the direction of movement shown in Fig. 8, the crevasses at the feather-shaped feature are likely to open and move more easily than those at the oval feature, resulting in large increase rates.

\section{Discussion}

4.1 Meteorological factor related to temporal increases in crevasse area

The increase rates for crevasse area are variable over time (bold lines in Fig. 11(a)). To explain this variability, we examined its relationship with air temperature at 3-hour in- 
(a)

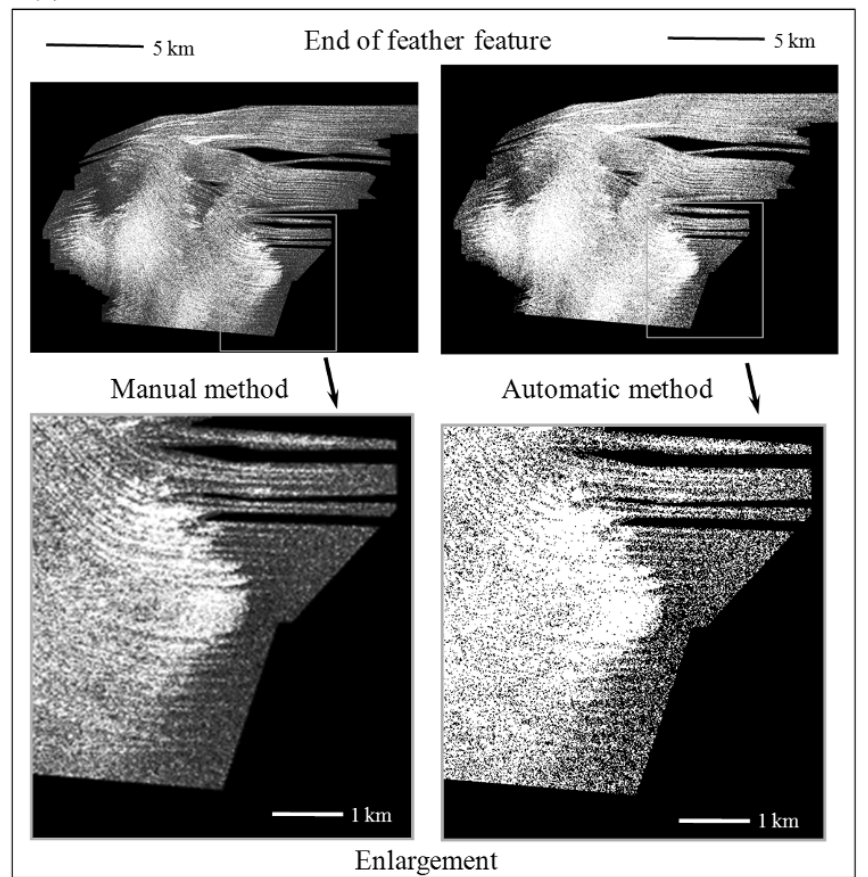

(b)

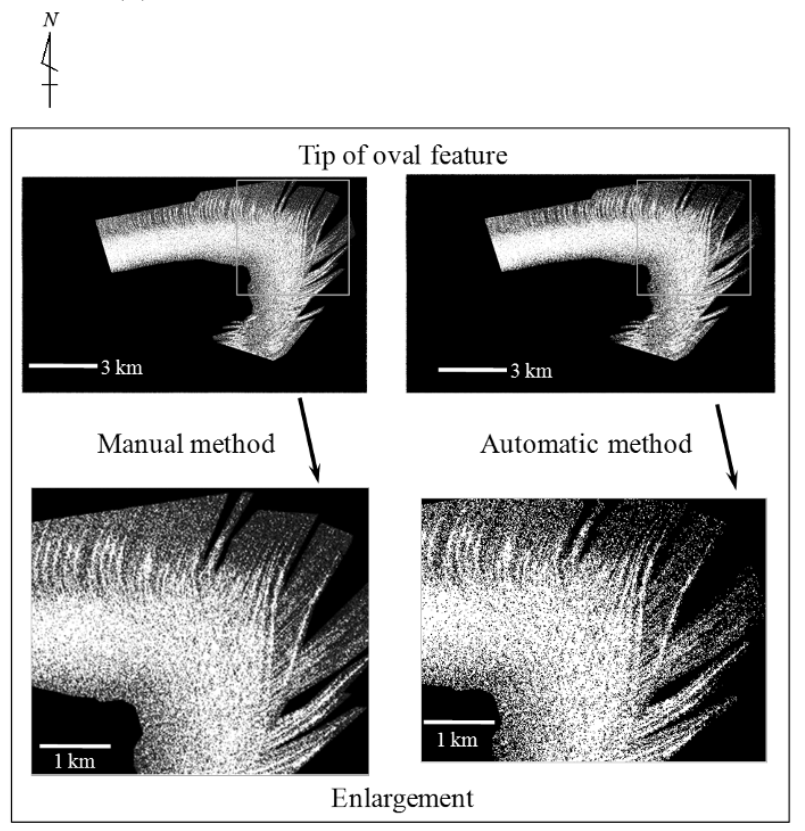

Fig. 10. Comparison of manual and automatic methods of determining the threshold value in the binarization of a SAR intensity image (December 1991), focusing on crevasses (a) at the end of the feather-shaped feature and (b) at the tip of the oval feature.

tervals $\left({ }^{\circ} \mathrm{C}\right)$ recorded at Neumeyer Station $\left(70.6^{\circ} \mathrm{S}, 8.3^{\circ} \mathrm{W}\right.$; see Fig. 1(a)). Neumeyer Station is the closest station to the present study area that continuously observes surface synoptic data, and monthly average air temperature (thin solid line in Fig. 11(a)) may be a proxy of regional-scale climatic (or environmental) change.

In Fig. 11(a), monthly average temperatures are superimposed on data regarding the size of crevasse areas. Temporal changes in crevasse areas at the feather-shaped feature are characterized by a slight increase from October 1991 to August 1994, a large increase until January 1997, a gentle increase thereafter, and nally the next large increase from March to August of 2000. There appears to be no correlation between monthly mean air temperature and the observed increase in crevasse area. Therefore, we examined additional details of temperature change. Figure 11(b) shows temporal changes in temperature (3-hour interval data) during 1996 and 1997 at Neumeyer Station. For both years, the annual trend in temperature describes a convex shape, although with large uctuations. Of note, once the minimum wintertime temperature has been attained, it shows a rapid increase to a local maximum within about 2 weeks of the minimum. To clearly show this temperature jump, we smoothed the temperature data. The smoothing intensity is approximately equal to a 1-week moving average. The smoothed data (red lines in Fig. 11(b)) are superposed onto the original data. We focus on the temperature difference between the wintertime minimum and the following local maximum, which we de ne as $\Delta T$ (Fig. 11(b)).

To quantitatively assess the effect of $\Delta T$ on the observed increase in crevasse area, we calculated the increase in crevasse area between consecutive images, $\Delta S$, and exam- ined its relation to $\Delta T$. Table 2 lists the ve examined SAR data pairs and their acquisition dates. In the case that the period between acquisition dates for a pair includes the minimum temperature for the year, the largest $\Delta T$ is chosen for the pair. For example, pair 3 (acquisition dates of $21 \mathrm{Au}$ gust 1994 and 31 January 1997) includes three $\Delta T$ s (those for 1994,1995 , and 1996). Because the $\Delta T$ in 1996 was the largest among them, it is used to correlate with the $\Delta S$ of pair 3. The same procedure was applied to pairs 2 and 5, to which the $\Delta T$ s for 1992 and 1997 were assigned, respectively. For pairs 1 and 5, whose intervals are less than 1 year, $\Delta T$ was selected as the largest 2-week increase in temperature after 21 October 1991 (pair 1) and the largest 2 -week increase in temperature in 2000 , between the acquisition dates (pair 5).

Figure 12 shows the relationship between $\Delta S$ and $\Delta T$ for the oval and feather-shaped features, which show negative and positive correlations, respectively. Because $\Delta S$ is much larger in the case of the feather-shaped feature, we focus on this feature rather than the oval feature. Despite the limited number of data points, the relationship can be approximated by an exponential function. The sensitivity of the crevasse area to temperature, which is approximated as $\Delta S$ divided by $\Delta T$, is roughly estimated to be $0.4 \mathrm{~km}^{2} /{ }^{\circ} \mathrm{C}$ for $\Delta T$ less than $17^{\circ} \mathrm{C}$, and $4 \mathrm{~km}^{2} /{ }^{\circ} \mathrm{C}$ for $\Delta T$ higher than $17^{\circ} \mathrm{C}$. Crevasse generation and extension are controlled by the change in stress eld, in particular increase of tensile stress near the glacier surface, not by the change in air temperature. Therefore, $\Delta T$ cannot be related directly to a factor that accelerates crevasse generation and extension. Figure 12 is merely an observation fact. However, crevasse depth is usually limited to $30 \mathrm{~m}$, and surface air temperature variation reaches a skin depth of about the same depth 
(a)

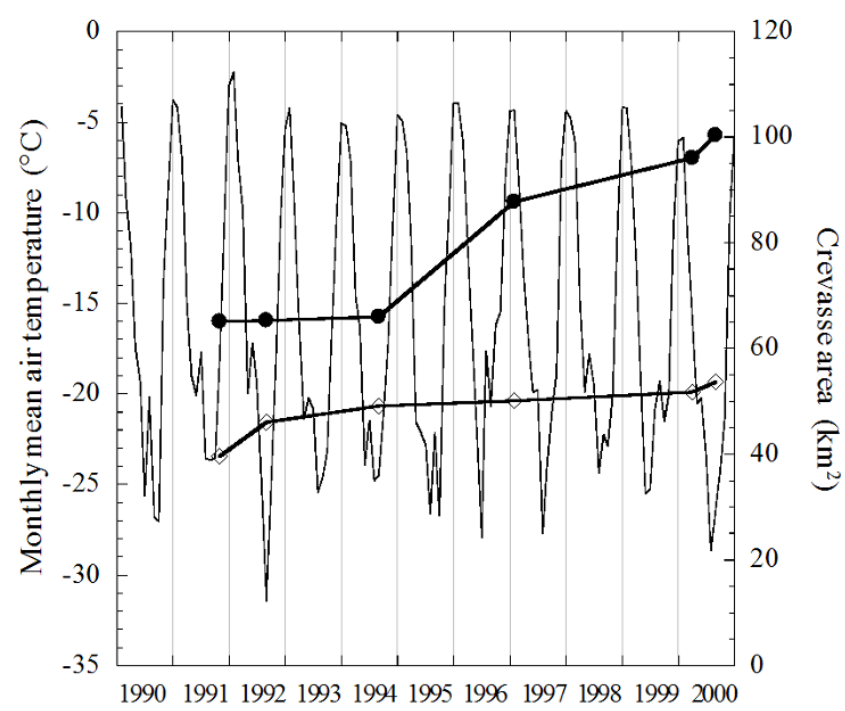

(b)
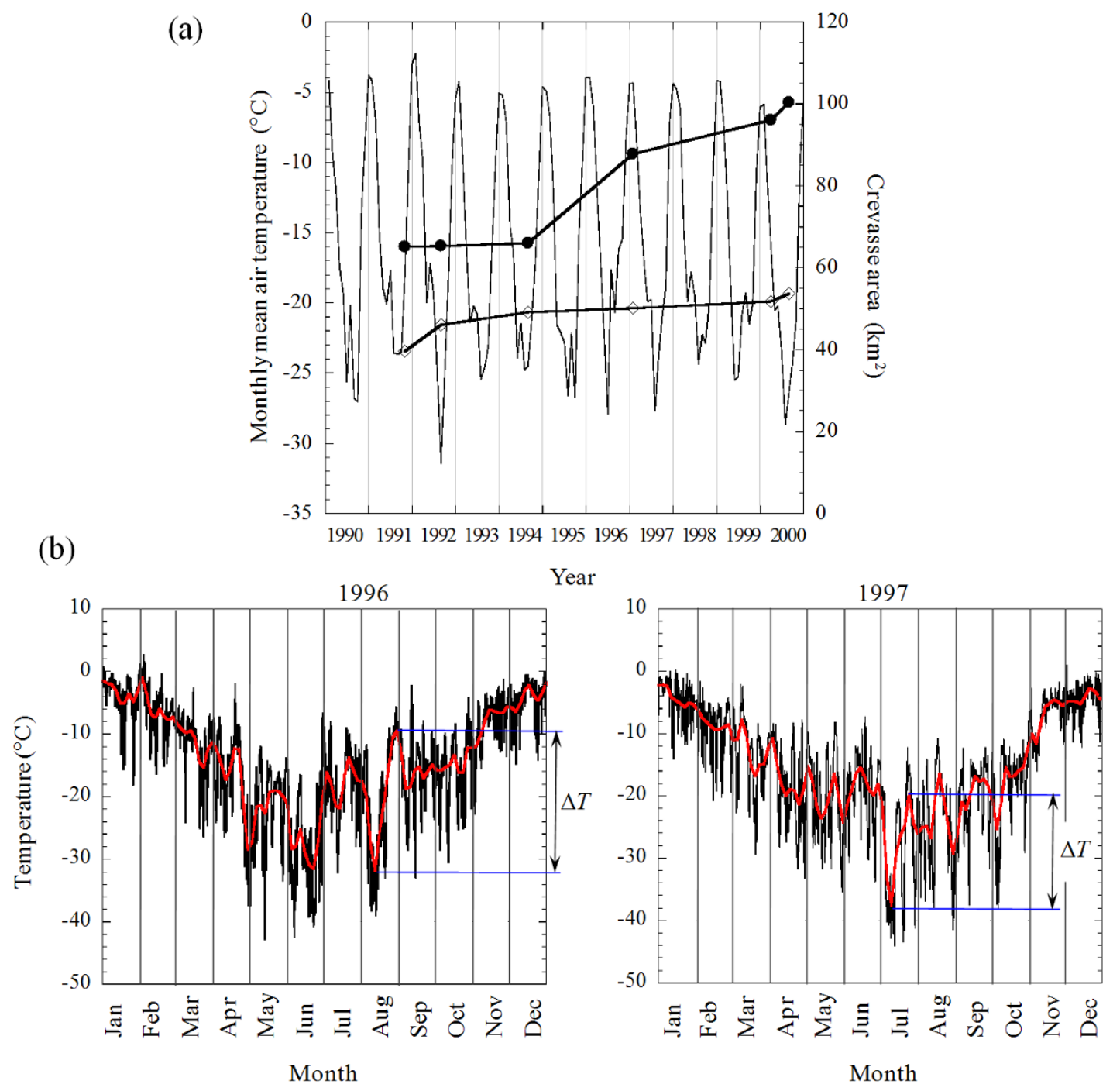

Fig. 11. (a) Temporal changes in crevasse area at the feather-shaped (black dots) and oval (white diamonds) features. The crevasses were extracted using the manual thresholding method in binarization of the SAR image. The patterns of change are compared with monthly mean air temperature $\left({ }^{\circ}\right.$ C) recorded at Neumeyer Station. (b) Temperature data (black lines, collected at 3-hour intervals) for 1996 and 1997 at Neumeyer Station and smoothed data (red lines, 1-week moving average). The magnitude of the increase in temperature from the wintertime minimum to a local maximum within about 2 weeks is defined as $\Delta T$.

Table 2. Acquisition dates for SAR data and years selected in defining $\Delta T$ for the five analyzed data pairs. For pairs 2, 3, and 4, we selected the largest $\Delta T$ among the years covered by the acquisition dates. For pairs 1 and 5, whose acquisition intervals were less than 1 year, we selected as $\Delta T$ the largest 2-week increase in temperature after 21 Oct. 1991 (pair 1) and the largest 2-week increase in temperature in 2000, between the acquisition dates (pair 5).

\begin{tabular}{cccc}
\hline No. & \multicolumn{2}{c}{ Acquisition dates of image pair } & Year for $\Delta T$ \\
\hline 1 & 21 Oct. 1991 & 15 Aug. 1992 & 1991 \\
\hline 2 & 15 Aug. 1992 & 21 Aug. 1994 & 1992 \\
\hline 3 & 21 Aug. 1994 & 31 Jan. 1997 & 1996 \\
\hline 4 & 31 Jan. 1997 & 14 Mar. 2000 & 1997 \\
\hline 5 & 14 Mar. 2000 & 3 Aug. 2000 & 2000 \\
\hline
\end{tabular}

$(30 \mathrm{~m})$, where mechanical properties of ice may respond sensitively to such temperature change. There might be a possibility that the change in stress field is connected with $\Delta T$ at the feather-shaped features due to high sensitivity to tensile stress and movability of glacier flow. Detailed future works are indispensable to confirm this possibility.

\subsection{Genesis of oval and feather-shaped features}

The Theron Mountains are located in the Karoo-Ferrar magmatic province that is the most voluminous igneous province over 4,000 km in length, associated with the breakup of Gondwana (Leat et al., 2006). Although of markedly different topographic scale, the map-view shape of the oval feature is similar to that of the Theron Mountains (see Fig. 1(b)). Analysis of the DEM compiled from InSAR data revealed that the oval shape is bounded by steep, high scarps, as is the case in the Theron Mountains. According to Brook (1972) and Marsh (1985), the Theron Mountains are composed of horizontally bedded sedimentary rocks intruded by dolerite sills up to $200 \mathrm{~m}$ thick. In terms of the 


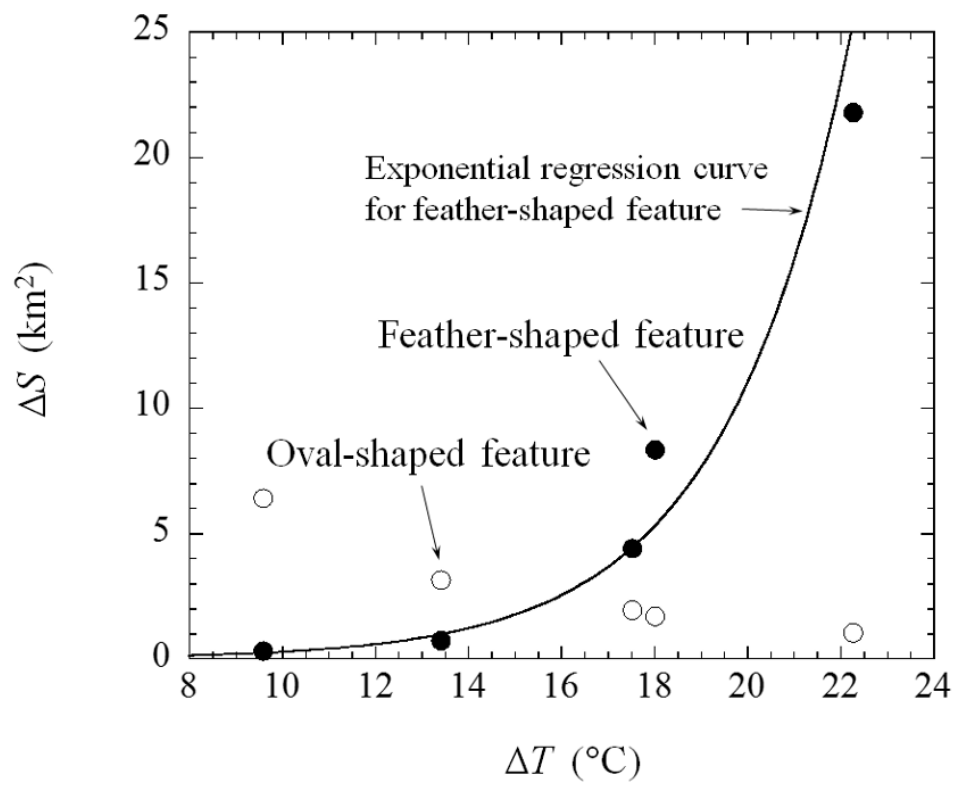

Fig. 12. Amount of increase in crevasse area between two images, $\Delta S$, compared with $\Delta T$ over the same interval. The acquisition dates of the SAR data and the year employed in selecting $\Delta T$ for the ve SAR pairs are provided in Table 2.

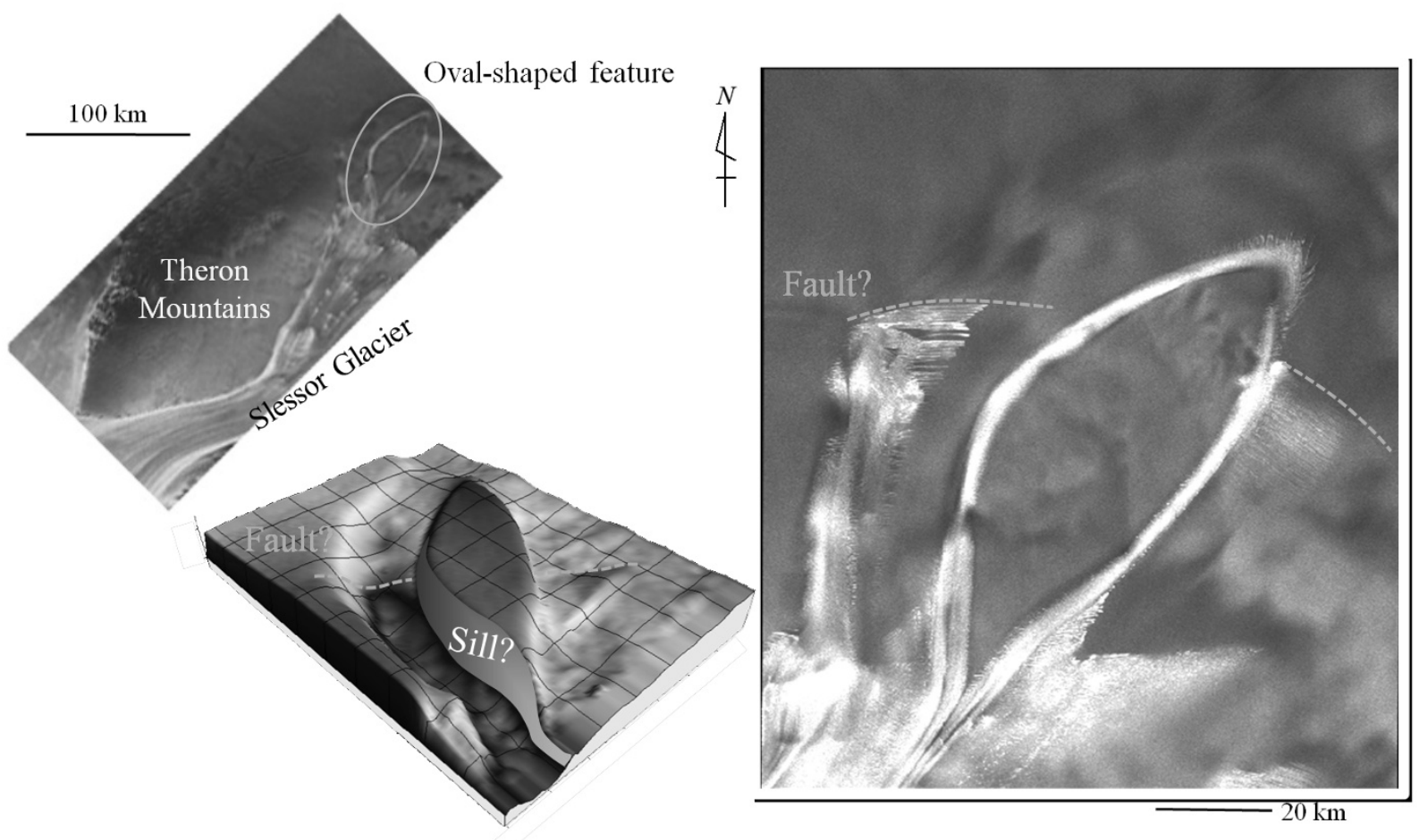

Fig. 13. Interpretation of a subglacial fault (dashed line) transecting the study area, extending from the end of the feather-shaped feature to the far side of the oval feature.

upper stream of the northern tributary of the Slessor Glacier, Shepherd et al. (2006) proposed that the highland area is underlain by a Jurassic dolerite sill (Ferrar sill), the same sill with the Theron Mountains, based on forward and inverse modeling of airborne magnetic data. In addition, the Theron Mountains are height of some $760 \mathrm{~m}$ (Leat et al., 2006), which coincides roughly with the elevation of the oval feature (Fig. 6).

Considering the similarities in shape and elevation, close proximity to the Theron Mountains, the location in the same magmatic province, and the continuity of the Ferrar sill, the oval feature is likely to be composed mainly of the same sill and sedimentary rocks as those found in the mountains. According to this interpretation, the oval feature was originally directly connected to the Theron Mountains, but became separated due to erosion associated with glacier ow.

The end of the feather-shaped feature is easily fractured, as demonstrated by the occurrence of closely spaced thin 
crevasses and the formation of new, large crevasses, as observed in SAR images (Fig. 7). This crevasse zone appears to be connected to the far side of the oval feature (Fig. 13), because enlargement of the images reveals that the white zone in the eastern side of the oval feature is also likely an assemblage of crevasses parallel to each other and to the broken line. Shepherd et al. (2006) reported several magnetic lineaments oriented near-perpendicular to the tributaries of the Slessor Glacier, which they interpreted as faults. The orientations of these lineaments are similar to those of crevasse zones that are laterally continuous with the lineaments. One explanation of these observations is that the presence of a fault, and its in uence on the subglacial topography, leads to the initiation of ice fractures and a subsequent concentration of crevasses.

\section{Conclusion}

Based on 10 SAR intensity images of ERS-1/2 AMI (6 acquisition dates from October 1991 to August 2000), temporal changes in crevasse patterns and their downglacier motion were analyzed in detail for the middle part of the northern tributary of the Slessor Glacier in East Antarctica, over an area of $60 \times 60 \mathrm{~km}$. This area contains an oval topographic feature that is $60 \mathrm{~km}$ along its long axis and $30 \mathrm{~km}$ along its short axis, and a feather-shaped feature that marks a zone of concentrated crevasses. The main results of this analysis are summarized as follows:

(1) Analysis of interferometric SAR data revealed that the oval feature is surrounded by a steep scarp of about $500 \mathrm{~m}$ in height to the west and $300 \mathrm{~m}$ in height to the east, and the valley in which the feather-shaped feature is located is surrounded by high scarps on both sides.

(2) In comparing manual and automatic methods for determining the threshold to be employed in extracting crevasses from SAR intensity images by binarization, the manual method was found to be more effective in extracting crevasses that are thin, closely distributed, and show variable DN values according to the degree of fracturing. The size of crevasse areas has increased over time at the end of the feather-shaped feature and at the tip of the oval feature, although the magnitude of increase is 3.6 times greater on the average at the feather-shaped feature.

(3) The most rapid increase in wintertime temperature within a 2 -week period shows a correlation with the observed increase in crevasse area which was approximated by an exponential function. One explanation of this nding is rapid softening of the ice body. This indicates that a rapid increase in wintertime temperature leads to accelerated crevasse generation and extension.

(4) Considering the similarity in shape and close proximity to the Theron Mountains, the oval feature is thought to be composed mainly of a Jurassic sill and sedimentary rocks, as with the Theron Mountains. The occurrence of a fault in the subglacial topography may have led to the initiation of ice fractures and a subsequent concentration of crevasses at the end of the feather- shaped feature. Consequently, the fault may be sensitively related with the generation of crevasses.

Acknowledgments. This study was carried out as a joint scienti c research program (2005-2007) between Kochi Women's University, Kumamoto University (the rst author's previous afliation) and the National Institute of Polar Research (NIPR) in Tokyo. The authors express their sincere thanks to Dr. Tsutomu Yamanokuchi and Dr. Nobuhiro Tomiyama of the Remote Sensing Technology Center of Japan for valuable instructions regarding the analysis of SAR data. Sincere thanks are extended to Dr. Gert König-Langlo of Alfred Wegener Institute for Polar and Marine Research for providing temperature data recorded at Neumeyer Station, and Dr. Shin Sugiyama for the valuable comments and the detailed suggestions that helped improve the clarity of the manuscript. The SAR data used in this study were received by JARE members at Syowa Station, and archived and supplied to NIPR from JAXA under the terms of a scienti c agreement between the organizations.

\section{References}

Brook, D., Stratigraphy of the Theron Mountains, British Ant. Surv. Bull., 29, 67-90, 1972.

Goldstein, R. M., H. Engelhardt, B. Kamb, and R. M. Frolich, Satellite radar interferometry for monitoring ice sheet motion: Application to an Antarctic ice stream, Science, 262, 1525-1530, 1993.

Gray, A. L., N. Short, K. Matter, and K. C. Jezek, Velocities and ux of the Filchner ice shelf and its tributaries determined from speckle tracking interferometry, Can. J. Rem. Sens., 27, 193-205, 2001.

Jezek, K. C., The RADARSAT-1 Antarctic Mapping Project, Byrd Polar Research Center Report, 22, 64 pp., 2008.

Joughin, I., W. Abdalati, and M. Fahnestock, Large uctuations in speed on Greenland's Jakobshavn Isbræ, Nature, 432, 608-610, 2004.

Kim, K., K. C. Jezek, and H. Liu, Orthorecti ed image mosaic of Antarctica from 1963 Argon satellite photograpghy: Image processing and glaciological applications, Int. J. Rem. Sens., 28, 5357-5373, 2007.

Leat, P., A. V. Lutinnen, B. C. Storey, and I. Millar, Sills of the Theron Mountains, Antarctica: Evidence for long distance transport of ma c magmas during Gondwana break-up, in Dyke Swarms: Time Markers of Crustal Evolution, edited by E. Hanski, S. Mertanen, T. Ramo, and J. Vuollo, 183-199, Taylor and Francis, 2006.

Liu, H., K. C. Jezek, B. Li, and Z. Zhao, Radarsat Antarctic Mapping Project Digital Elevation Model Version 2, National Snow and Ice Data Center, Digital Media, Boulder, 2001.

Marsh, P. D., Ice surface and bedrock topography in Coats Land and part of Dronning Maud Land, Antarctica, from satellite imagery, British Ant. Surv. Bull., 68, 19-36, 1985.

Otsu, N., An automatic threshold selection method based on discrimination and least squares criteria, Trans. Inst. Electr. Comm. Eng. Jpn., J63-D, 349-356, 1980 (in Japanese with English abstract).

Scambos, T. A., M. J. Dutkiewicz, J. C. Wilson, and R. A. Bindschadler, Application of image cross-correlation to the measurement of glacier velocity using satellite image data, Remote Sens. Environ., 42, 177-186, 1992.

Shepherd, T., J. L. Bamber, and F. Ferraccioli, Subglacial geology in Coats Land, East Antarctica, revealed by airborne magnetic and radar sounding, Earth Planet. Sci. Lett., 244, 323-335, 2006.

Solomon, S., D. Qin, M. Manning, M. Marquis, K. Averyt, M. M. B. Tignor, H. L. M. Miller Jr., and Z. Chen (eds.), Climate Change 2007The Physical Science Basis, Contribution of Working Group I to the Fourth Assessment Report of the IPCC, Cambridge University Press, New York, 2007.

Whillans, I. M. and Y.-H. Tseng, Automatic tracking of crevasses on satellite images, Cold Reg. Sci. Tech., 23, 201-214, 1995.

K. Koike (e-mail: koike.katsuaki.5x@kyoto-u.ac.jp), H. Yoshida, M. Omura, K. Shibuya, and K. Doi 